"Abstracts from the Meteorological Observations taken at the Stations of the Royal Engineers (including $\mathrm{I}_{5}$ Colonial Stations) in the Year 1853-4, with Notes on Meteorological Subjects."

"Abstracts from the Meteorological Observations taken at the Stations of the Royal Engineers (comprising I3 British and 18 Colonial Stations) in the Years 1853-4, I8 $54-5,1855^{-6}$, I $85^{6-7}, 1857^{-8}$, and $185^{8}--9$.'

"Abstracts from the Meteorological Observations taken in the Years $1860-6 \mathrm{r}$, at the Royal Engineer Office, New Westminster, British Columbia."

These volumes will be issued without payment.

I may also mention at the same time that the Meteorological Committee, acting in accordance with the recommendation of the fourth International Conference on Scientific Aëronautics, has undertaken to subscribe for a number of copies of the international publication of the observations of the upper air on the "international days," which will be issued by Prof. Hergesell, the president of the commission. I shall be glad to know whether any scientific institution or library wishes to subscribe for a copy of this publication. The amount of the subscription is $\mathrm{I}$. per annum. W. N. SHaW.

\section{The Breeding Habits of the Tsetse-fly.}

I sHould be greatly obliged if you could find space in your columns for the following extracts from a letter which I have received from my friend Dr. A. G. Bagshawe announcing the discovery, I believe for the first time, of the pupæ of the tsetse-fly (Glossina palpalis) in nature. As this species of fly is now known to be the agent which disseminates the infection of sleeping sickness, any discoveries relating to its breeding habits are of the utmost importance from the point of view of devising measures for extirpating the fly or checking its increase. Together with my colleagues Lieuts. Gray and Tulloch, I spent a great deal of time, when I was in Entebbe, in searching for the pupæ of the fly, and we offered the native boys a rupee each for them, but all our efforts to find them in nature were unsuccessful, although captive flies deposited great numbers of pupæ in our cages. I ought, perhaps, to explain at this point that the tsetse-fly is viviparous, and produces a full-grown larva, one at a time; the larva is of a light yellowish tint when born, and wriggles about actively for an hour or so, and then turns in a short time to a dark brown pupa, about the size of a grain of wheat.

Dr. Bagshawe, who is already well known for the botanical collections he has sent home, has succeeded where we failed, and as I do not know what steps he has taken to secure the priority for this most important discovery, I hasten to make it public on his behalf. It will be seen that the pupæ have been found in the banana plantations. Since bananas are the staple food of the Baganda, it would be impossible to destroy the plantations without creating a famine. I may mention, however, that we found the tsetse-fly swarming on the deserted island of $\mathrm{Kimmi}$, on the Victoria Nyanza, where there were no plantations, so that this is perhaps not its only breeding place.

E. A. Minchin.

Lister Institute of Preventive Medicine, October 17 .

(Extract from Dr. Bagshawe's Letter.)

"On August 29 I got them [the pupæ] at last. I had marked down a particular spot as likely, and had pitched my camp near by to search. Along the lake shore for about roo yards was a belt of bananas 10-20 (40?) yards in width, and behind that undergrowth, going back roo yards or more. Fly were thick and bothered one up to sunset.

"On the second day one of the porters I had coached brought me a pupa while I was searching a hole in a tree. $\mathrm{He}$ had found it among the banana rootlets. I searched there at once, and soon found some empty pupa cases. The next day I had a lot of my people at work and 5. pupæ were found, all in the loose crumbling soil round the bananas. In the scrub behind there are none to be got. . . .

"I made a series of experiments latelv to find out how long a stretch of river the individual fly haunts. I started on the assumption that a fly with five legs is as good as one with six, and if one snipped off a piece of a known leg that fly could be identified when caught again. Six series of experiments could be made. It worked admirably. The experiments want repeating on a larger scale (I hope to do it on the Semliki), but I have shown clearly that the range is at least a mile. This is the reason why the breeding places have eluded search so long.

" (Signed) Arthur G. Bagshawe.

"Albert Edward Lake, September I, 1906."

\section{Suspended Germination of Seeds.}

IN Mr. Claridge Druce's !etter in NATURE of October II he rightly remarks that in order to prove the suspended germination of seeds. over long periods, instances are required in which the factors of wind-carried seeds, \&c., can be with some certainty eliminated. The following case, though not absolutely conclusive, may still be of interest.

Personally I am of opinion that the seed of Digitalis does preserve its germinating power for a considerable time. A few years ago I cleared a space, speaking from memory, of say forty yards by thirty yards, occupied by old Portugal laurels 25 feet to 30 feet high, planted fully sixty years ago, with Rhod. ponticum lining the path in front; the space, except on the path side, is surrounded by thick coverts. The nearest growing foxgloves were to the west along a 6-feet path running parallel with the long side of the cleared area, and distant, say, ten yards; both sides of this intervening space are lined by old rhododendrons; seed blown along would fall on the path or the edge of the clearing. The laurels were removed in January and February, when all, or nearly all, the seed would have been shed. Notwithstanding this, the next spring the whole of the cleared ground was covered with a uniform carpet of seedlings, practically hiding the bare ground. It seems to me that, even if some wind-blown seed penetrated the evergreen barrier, the seedlings would have appeared in patches.

I have known many other somewhat similar instances, but none quite so specialised as the above. I may add that the spot is exceptionally protected from wind, having tall forest trees on all sides.

Smeaton-Hepburn, Prestonkirk.

Archibald Buchan-Hepburn.

\section{Biometry and Biology.}

Owing to the proof of my letter in last week's NATURE reaching me too late for careful revision, one or two slips escaped notice. Of these; I would wish to direct attention to the interchange of the words intra-racial and inter-racia in the second paragraph on p. 609 (column I, line I4).

Biometric Laboratory, University College, London, October I9.

\section{SPEED AND STABILITY IN RAILWAY TRAVELLING.}

THE Salisbury railway accident, being followed after no very long period by the somewhat similar disaster at Grantham, undoubtedly raised a feeling of considerable uneasiness in the public mind. The recent publication by the Board of Trade of Major Pringle's report on the former calamity should do something to allay this apprehension, if only because it shows that the cause of the derailment of the train was not "mysterious," but is fully to be explained. That the evil we know is less alarming than one which vaguely threatens is a fact for which we have classic authority.

The accident occurred on July I at the Salisbury Station of the London and South-Western Railway, the train being the special boat express from Plymouth to London, carrying passengers who had arrived by the American liner New York. The train consisted of four eight-wheeled vehicles hauled by a fourNo. I 930 , vกт.. 747 
coupled engine with a leading bogie, having an eightwheeled bogie tender. The coaches were not of excessive length, the longest being 48 feet, and all were on bogies; the engine was one of the company's usual modern express type, and although the boiler is mounted higher than was formerly the practice, the train was well calculated to run safely round curves under usual conditions : yet it was a curve that caused the accident. In saying this we are not verbally in agreement with Major Pringle's report or with the verdict of the coroner's jury at the inquest on the unfortunate victims, both of which attribute the accident to excessive speed. No doubt the speed at which the curve was taken was too high, but if the curve had not been so sharp the speed would have been perfectly safe; in fact, it was the curve which was the abnormal feature, the speed being ordinary for ordinary conditions. It may seem like splitting hairs to cavil over terms in this manner, but the matter has greater significance than may appear. If we allow the accident to have been due simply to speed, then the railway authorities have done all that they can do when they order driversas they always have done-to reduce speed to within safe limits; but if it is stated that the accident was due to excessive curvature of track, then the company will appear not to have done all that is possible until they flatten the curve. Whether the danger warrants the expenditure is another matter, but we may remember that so long as drivers are human and liable to err, the chance of disaster is always present whilst such an abnormal curve exists on a main line over which express trains run; in other words, if the Salisbury curve did not exist accident from the same cause would be impossible.

Speed is always a doubtful point in the elucidation of the cause of accident, but there is no doubt, from the evidence at the inquest and the Board of Trade inquiry, that the train was travelling very greatly in excess of the thirty miles an hour laid down by the regulations as safe for the curve immediately to the cast of Salisbury station. One witness estimated the speed to have been as high as seventy miles an hour, and Major Pringle considers that possibly this may not have been an extravagant estimate. When the engine and tender left the line it came into violent contact with a milk train moving on the down line, and the wreckage also struck a light engine standing in a bay close by. Particulars of the loss of life have been fully published, and it will be sufficient to say that on the express twenty-four passengers were killed, seven were seriously injured, the engine-driver and fireman were killed, and a ticket collector and two waiters on the dining car were injured. The guard of the milk train and the fireman of the light engine were also killed, and the driver was badly scalded.

The chief interest of Major Pringle's report, as in all reports of this nature, centres in his conclusion as to the probable cause of the accident. Speaking at large, there is no doubt, as we have stated, but that the disaster was due to high speed on an awkward curve, and the evidence all points to the fact that the engine and tender turned over bodily; how the forces set up acted so as to bring about the result is the problem that remains to be solved.

According to the plan of this part of the line, given in the report, the up line is straight through the station, but at the eastern end of the platform a curve to the left of ten chains radius (compound) extenils for a distance of about ninety-two yards. In the body of the report is a statement attributing a radius of eight chains to the curve, this representing the sharpest part of it. There is a rising gradient of $\mathrm{I}$ in 158 , and the maximum superelevation on the curve is $3^{\frac{1}{2}}$ inches. It was on this part of the line that the accident occurred, the overturned engine being found at the termination of the curve, and just in front of facing points with reverse curves of $7 \frac{1}{2}$ chains radius; naturally there could be no superelevation at the points. The report states that the three leading vehicles of the express were ovęrturned in various directions, the frames stripped of woodwork and completely destroyed. The fourth vehicle fared little better. Comparatively little damage was done to the last vehicle, which came to rest in an upright position, with the last pair of wheels on the proper rails. The engine and tender were both overturned on their right sides, but less damage was done than might have been expected, and the engine was shortly afterwards hauled to Nine Elms on its own wheels. Five vans of the milk train were completely destroyed, and five were damaged. This destruction of rolling-stock was accompanied by remarkably little danage to permanent way on the up line over which the express was running, but a length of about forty yards of the down line was torn out and destroyed.

The weight of the engine was nearly 54 tons (53 tons $19 \mathrm{cwt}$ ), 16 tons $17 \mathrm{cwt}$. being on the leading bogie, Ig tons $2 \mathrm{cwt}$. on the leading driving axle, and 18 tons on the trailing axle. The tender weighed 44 tons 17 cwt., 23 tons 2 cwt. being on the leading bogie, and $2 \mathrm{I}$ tons $\mathrm{I}_{5}$ cwt. on the trailing bogie. The centre of gravity of the engine was calculated at about 5 feet above the rail-level, and that of the tender at about $4^{\frac{3}{4}}$ feet.

So far we have most of the chief data generally at command for calculating what would be the limit of safe speed for travelling over the part of the line where the accident occurred. Calculations for the centre of gravity of an engine are somewhat tedious, even when all data are at command, and the figures given appear somewhat low for an engine of the type. In former days this would have been of less consequence, but the tendency to raise the boiler, so that the chimney becomes nothing more than a " frill round a hole" - as a railway engineer recently said-makes the centre of gravity a factor that needs more attention, although the effect in this respect of the modern high boiler is far more apparent than real.

It is unfortunate that our chief railways were designed for lower speeds than are now required, and altogether for more primitive conditions; thus it is possible that when Salisbury Station was built it was not anticipated that a train would ever run through, and the curve of 8 chains would be without danger for a stopping train.

Major Pringle says that the engine in question, with a centre of gravity 5 feet above the rails, when traversing a curve of 8 chains, would be in unstable equilibrium at a speed of about sixty-seven to sixtyeight miles per hour, even if full allowance were made for the beneficial effect of $3^{\frac{1}{2}}$ inches superelevation. Major Pringle does not give his calculations, but, as he says, the result may be taken as agreeing with modern formulæ. The rule $\frac{W^{2}}{I^{2} 25} \mathrm{R}=\mathrm{E}$, where $\mathrm{W}=$ width of gauge in feet, $\mathrm{V}=$ velocity in miles per hour, $\mathrm{R}=$ radius of curve in feet, and $\mathrm{E}=$ elevation of outer rail in inches; or if the speed $\mathrm{V}$ were expressed in feet per second the formula would become $\mathrm{W} \mathrm{V} / g \mathrm{R}$, where $g$ is 32.2 . If the formula were used to calculate the superelevation for a speed of sixty miles per hour, it would give superelevation of 25.6 inches; on the other hand, at the speed of thirty miles an hour-that laid down as a maximum by the railway company's engineers-the rule would give

NO. I 930, VOL. 74] 
superelevation of 6.4 inches. The maximum superelevation on the South-Western Railway is 6 inches, and it is, of course, altogether impossible to work with any such superelevation as more than 2 feet. It will be understood that the whole of the constraining force required to keep the engine moving in the curve is supplied by the resolved component of the weight of the engine acting parallel to the plane of the radius towards the centre of curvature.

It will be evident, therefore, that superelevation is a remedy of limited efficacy for a serious defect. The centrifugal force at sixty miles per hour (a speed that the evidence of figures shows to have been exceeded, but which we adopt as a convenient standard) would be $\frac{54 \times 88^{2}}{32.2 \times 528}$, or, approximately, $24 \frac{1}{2}$ tons (24.597).

The accompanying diagram (Fig. I) illustrates the resultant of the two opposing forces acting on the engine.

$\mathrm{M}=$ centre of gravity of the engine 5 feet above raillevel. The line $\mathrm{MQ}=$ the weight of the engine, and $\mathrm{MF}=$ the centrifugal force at sixty miles an hour to the same scale. Completing the parallelogram $M F R Q$, then $M R=$ the resultant of the two forces. Producing MR, it cuts the rail-level at the point $H$, which is 5.29 inches inside the outer rail; $\mathrm{AE}$ is the superelevation. There would only be, therefore,

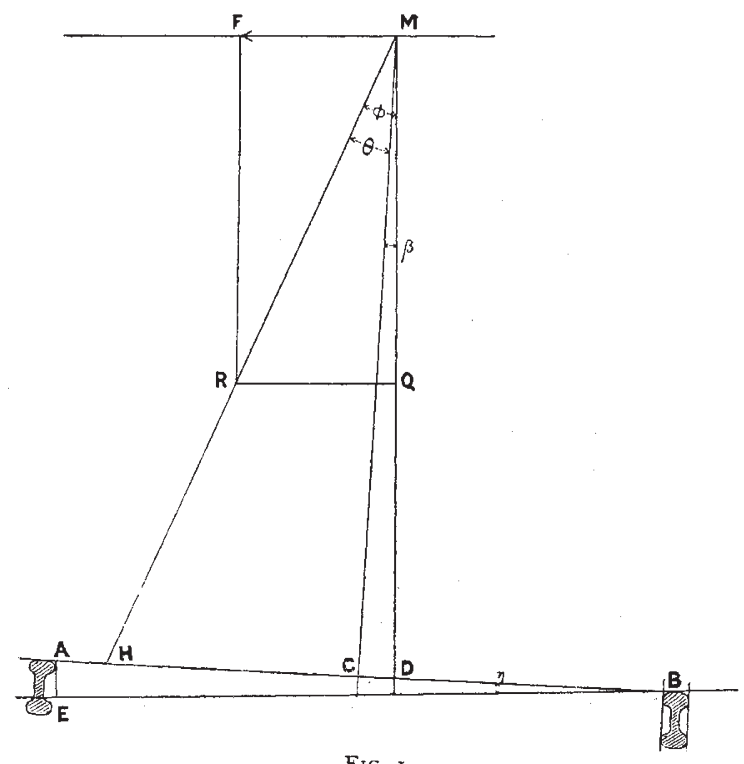

about 5 inches between the points $A$ and $H$. The narrowness of the margin of safety with the data assumed is indicated very clearly in the diagram by the nearness of $\mathrm{H}$ to $\mathrm{A}$; should $\mathrm{H}$ coincide with $\mathrm{A}$, the engine is just on the point of turning over.

The working out of the problem is as follows :--.

$$
\begin{aligned}
& \mathrm{MQ}=54 \text { tons. } \\
& \begin{array}{l}
M Q=54 \text { tons } \\
M F=24.596 \text { tons. }
\end{array} \\
& \mathrm{MC}=60 \text { inches. } \\
& \mathrm{AE}=3.5 \text { inches. } \\
& \mathrm{AB}=56 \cdot 5 \text { inches. } \\
& \tan \phi=\frac{\mathrm{MF}}{\mathrm{MQ}}=\frac{24.596}{54}=0^{\circ} 45548 \\
& \phi=24^{\circ} 29^{\prime} \\
& \text { sine } \beta=\text { sine } \eta=\frac{\mathrm{AE}}{\mathrm{AB}}=\frac{3.5}{56.5}=0.06 \mathrm{Ig} \\
& \beta=3^{\circ} 33^{\prime} \\
& \theta=\phi-\beta=24^{\circ} 29^{\prime}-3^{\circ} 33^{\prime}=20^{\circ} 56^{\prime} \\
& \mathrm{CH}=\mathrm{MC} \tan \phi=60^{\circ} \times 0^{\circ} 383=23 \text { (app.) } \\
& \mathrm{AH}=28 \cdot 25-23=54 \text { inches. }
\end{aligned}
$$

Working backwards with the same data, and assuming the resultant to pass through $A$, it will be found that the critical speed would be practically sixty-six miles per hour.

In order to calculate $\mathrm{CH}$ quickly and with an approximation sufficient for practical purposes, the above working may be very much simplified by the following formula, which has been suggested by Prof. Dalby :-

$$
\mathrm{CH}=h\left(\frac{\mathrm{V}^{2}}{g \overline{\mathrm{R}}}-\frac{e}{\mathrm{G}}\right) \text {, where } e=\text { superelevation in inches, }
$$

$\mathrm{G}=$ the gauge in inches, $\mathrm{V}=$ the velocity in feet per second, $g=32 \cdot 2, \mathrm{R}=$ radius of curve in feet, $h=$ height of cenire of gravity of engine above the rail level in feet.

The way in which the formula is obtained from Fig. I is as follows :-

$$
\begin{aligned}
\beta= & \frac{\mathrm{AE}}{\mathrm{AB}}=\frac{e}{\mathrm{G}} \text { app. } \\
\phi= & \frac{\mathrm{QR}}{\mathrm{MQ}}=\frac{\mathrm{WV}}{g \mathrm{R}} \div \mathrm{W}=\frac{\mathrm{V}^{2}}{g \mathrm{R}} \text { very approximately. } \\
& \text { Therefore } \theta=\phi-\beta=\mathrm{V}^{2}-e \text { approximately. } \\
& \text { Therefore } \mathrm{CH}=\mathrm{CM} \times(\phi-\theta)=h\left(\frac{\mathrm{V}^{2}}{g \mathrm{R}}-\frac{e}{\mathrm{G}}\right) .
\end{aligned}
$$

The above gives a very nearly correct result when the point $\mathrm{H}$ is in the neighbourhood of $\mathrm{C}$, as it should be. The error increases as $\mathrm{H}$ approaches $\mathrm{A}$.

We may compare the value of $\mathrm{CH}$ obtained by the two methods; we have already shown by the exact method that $\mathrm{CH}=23$ inches. Applying the approximate formula $\mathrm{CH}=23.6$ inches.

From the foregoing calculations it would appear that if the train were travelling at a speed of more than sixty-six miles an hour the engine would turn over sideways, but it will be understood that deductions drawn in this way are not proof, though they may be evidence, of what has occurred. The speed of the train is, of course, a very indeterminate quantity; the maximum superelevation was, as stated, $3 \frac{1}{2}$ inches, but, to judge by the plan, this did not extend on the curve for a greater distance than about 5o feet, and it would appear that at the spot where the trouble commenced (to judge by the damage to the line) the superelevation was somewhat less. Again, in placing the position of the centre of gravity of the engine, there are various unknown factors which it would be necessary to take into consideration to enable a true result to be reached; for instance, there is the unequal compression of the springs causing lateral displacement of the centre of gravity, rush of water in the boiler, and the extent of wear of wheels and rails.

\section{G. R. Dunell.}

\section{ESTIMATION OF BLOOD-PRESSURE.}

$T$ HE subject of blood-pressure is one of great interest both to the physiologist and the clinical physician. By blood-pressure is meant the pressure which the blood exerts on the interior of the heart and blood-vessels, but it is chiefly with the vascular blood-pressure-arterial, capillary, and venous-that the physician deals. Our conception of intravascular pressure is facilitated by considering what happens when an aperture is made in an artery, capillary, or vein of a living animal. In the case of the artery the blood squirts out with considerable force, the height of the jet measuring the pressure exerted on the interior of the vessel. Experiment shows that the pressure falls slowly from the heart to the region of the smallest arteries, or arterioles, where there is a considerable fall, the pressure in the capillaries and

No. 1930, voL. 74] 